\title{
The multi-target drug BAI induces apoptosis in various human cancer cells through modulation of $\mathrm{Bcl}-\mathrm{xL}$ protein
}

\author{
SHIN KIM ${ }^{1,2}$, DONG EUN KIM ${ }^{1}$, TAEG KYU KWON ${ }^{1,2}$, JINHO LEE $^{3}$ and JONG-WOOK PARK ${ }^{1,2}$ \\ ${ }^{1}$ Department of Immunology, ${ }^{2}$ Institute of Medical Science, School of Medicine and \\ ${ }^{3}$ Department of Chemistry, Keimyung University, Daegu 42601, Republic of Korea
}

Received August 17, 2016; Accepted October 21, 2016

DOI: $10.3892 /$ ijo.2016.3758

\begin{abstract}
Previous studies have demonstrated the anticancer effects of the newly developed cyclin-dependent kinase inhibitor BAI in various cancer cells. However, the molecular mechanisms of the cellular effects induced by BAI have not been fully elucidated. The objective of this study was to investigate the mechanisms underlying the regulation of B cell lymphoma-2 (Bcl-2) family proteins in BAI-induced apoptosis of cancer cells. BAI induced poly(ADP-ribose) polymerase cleavage and DEVDase activation dose- and time-dependently. However, BAI-induced apoptosis was not involved in reactive oxygen species generation or mitogenactivated protein kinases pathways. On the other hand, BAI reduced the mitochondrial membrane potential $\left(\Delta \Psi_{\mathrm{m}}\right)$ dose- and time-dependently, and induced the release of apoptosis-inducing factor (AIF) and cytochrome $c$ from mitochondria in A549 and Caki cells. Furthermore, BAI-induced apoptosis was strongly associated with downregulation of B-cell lymphoma-extra large (Bcl-xL), but not Bcl-2, and BAI modulated the interactions among p53 and Bcl-2 family proteins in human cancer cells. Taken together, these results revealed that the regulations of $\mathrm{Bcl}-2$ family proteins are correlated with BAI-induced apoptosis, suggesting that BAI is a potential multi-target agent of cancer.
\end{abstract}

Correspondence to: Dr Shin Kim or Professor Jong-Wook Park, Department of Immunology, School of Medicine, Keimyung University, 1095 Dalgubeol-daero, Daegu 42601, Republic of Korea E-mail: god98005@dsmc.or.kr

E-mail: j303nih@dsmc.or.kr

Abbreviations: Bcl-2, B cell lymphoma-2; Bcl-xL, B-cell lymphomaextra large; PARP, poly(ADP-ribose) polymerase; ROS, reactive oxygen species; MAPK, mitogen-activated protein kinases; MMP, mitochondrial membrane potential; z-VAD-fmk, benzyloxy carbonyVal-Ala-Asp-fluoromethyl ketone; NAC, N-acetylcysteine; GEE, glutathione; COXII, cytochrome $c$ oxidase subunit II; IP, immunoprecipitate; AIF, apoptosis-inducing factor

Key words: BAI, Bcl-xL, Bax, p53, PUMA, mitochondrial membrane potential, apoptosis

\section{Introduction}

Recent studies demonstrated that the novel cyclin-dependent kinase (cdk) inhibitor, 2-[1,1'biphenyl]-4-yl-N-[5-(1,1-dioxo$1 \lambda^{6}$-isothiazolidin-2-yl)-1H-indazol-3-yl]acetamide (BAI) has anticancer effects on various cancer cell lines, including A549, HCT116, Caki, AMC-HN 4, and AMC-HN-6 (1-3). Previous studies showed that BAI downregulated Mcl-1(L) at transcriptional level (2) and B cell lymphoma-2 (Bcl-2) (4). However, there are still major gaps in the understanding of BAI, particularly in terms of its apoptotic mechanisms.

Apoptosis, as an important mechanism of programmed cell death, is preserved among multi-cellular organisms and involved in various biological processes including development, maintenance of tissue homeostasis, and elimination of unwanted or damaged cells $(5,6)$. There are two major pathways of apoptosis: the pathway triggered via ligandbinding to the cell surface death receptors such as Fas (the extrinsic pathway) and the pathway in which pro-apoptotic Bcl-2 family proteins mediate the permeabilization of the mitochondrial outer membrane (the intrinsic pathway) (7). Bcl-2 family members regulate life/cell death, primarily via interactions between anti- and pro-apoptotic members (8). For example, PUMA, unique among $\mathrm{BH} 3$-only proteins, functions as a major mediator of pro-apoptotic p53 function by disrupting the interaction of $\mathrm{p} 53 / \mathrm{Bcl}-\mathrm{xL}$, resulting in apoptosis $(9,10)$. Therefore, modulating these proteins, such as Bcl-2 family proteins, PUMA, and p53, is a very promising therapeutic strategy in the development of compounds for anticancer effects.

In this study, we investigated the underlying mechanisms of Bcl-2 family proteins involved in BAI-induced apoptosis in human cancer cells. Our results revealed that the downregulation of Bcl-xL and the modulations of interactions among p53 and Bcl-2 family proteins may be involved in BAI-induced apoptosis in human cancer cells.

\section{Materials and methods}

Cell lines and culture. A549 human non-small cell lung cancer cells and HCT116 human colorectal carcinoma cells were obtained from the American Type Culture Collection (ATCC, Rockville, MD, USA) and grown in RPMI-1640 medium (WelGENE Inc., Daegu, Korea) supplemented with $10 \%$ heat- 
inactivated fetal bovine serum (FBS), 2 mM L-glutamine, $100 \mu \mathrm{g} / \mathrm{ml}$ streptomycin and $100 \mu \mathrm{g} / \mathrm{ml}$ penicillin. Caki human renal clear cell carcinoma cells were obtained from the ATCC and grown in Dulbecco's modified Eagle's medium (DMEM), containing 10\% heat-inactivated FBS, $20 \mathrm{mM}$ HEPES buffer and $100 \mu \mathrm{g} / \mathrm{ml}$ streptomycin and $100 \mu \mathrm{g} / \mathrm{ml}$ penicillin.

Drugs and materials. 2-[1,1'-biphenyl]-4-yl-N-[5-(1,1-dioxo$1 \lambda^{6}$-isothiazolidin-2-yl)-1H-indazol-3-yl]acetamide (BAI) was kindly supplied by Dr J.H. Lee (Keimyung University, Daegu, Korea). Anti-Bcl-xL (sc-634, 1:700), anti-AIF (sc-5586, 1:700), anti-p53 (sc-126, 1:1,000), anti-PUMA (sc-19187, 1:700), anti-cytochrome $c$ oxidase subunit II (sc-23983, 1:700), and anti-Bcl-2 (sc-783, 1:700) antibodies were purchased from Santa Cruz Biotechnology (Santa Cruz, CA, USA). Anti- $\beta$-actin (A5441, 1:2,000) antibody was purchased from Sigma Chemical Co. (St. Louis, MO, USA). Anti-poly(ADP-ribose) polymerase (PARP) (\#9542, 1:1,000) antibody was purchased from Cell Signaling Technology (Danvers, MA, USA). Anti-caspase-3 (610322, 1:1,000), anticytochrome $c$ (556433, 1:700), and anti-Bax (554104, 1:700) antibodies were purchased from BD Biosciences (Bedford, MA, USA). Benzyloxy carbony-Val-Ala-Asp-fluoromethyl ketone (z-VAD-fmk) was purchased from R\&D Systems (Minneapolis, MN, USA). PD-98059 (MEK inhibitor, PD), SP600125 (JNK inhibitor, SP), and SB-203580 (p38 MAP kinase inhibitor, SB) were purchased from Enzo Life Sciences (Farmingdale, NY, USA).

Western blot analysis. Cellular lysates were prepared by suspending $0.3 \times 10^{6}$ cells in $80 \mu 1$ of lysis buffer $(137 \mathrm{mM} \mathrm{NaCl}$, $15 \mathrm{mM}$ EGTA, $0.1 \mathrm{mM}$ sodium orthovanadate, $15 \mathrm{mM} \mathrm{MgCl}_{2}$, $0.1 \%$ Triton X-100, $25 \mathrm{mM}$ MOPS, $100 \mu \mathrm{M}$ phenylmethylsulfonyl fluoride and $20 \mu \mathrm{M}$ leupeptin, adjusted to $\mathrm{pH}$ 7.2). The cells were disrupted by vortexing and extracted at $4{ }^{\circ} \mathrm{C}$ for $30 \mathrm{~min}$. The proteins were electrotransferred to Immobilon-P membranes (Millipore Corp., Bedford, MA, USA). Detection of specific proteins was carried out with an ECL Western blotting kit according to the manufacturer's instructions (Millipore Corp.).

Cell viability assay. The anti-proliferative effect of the BAI on cancer cells was investigated using a live cell movie analyzer, JuLI ${ }^{\mathrm{TM}} \mathrm{Br}$ (NanoEnTek Inc., Seoul, Korea). Briefly, the cells were plated in 6-well culture plates at a density of $0.3 \times 10^{6}$ cells/well in medium and allowed to attach for $10 \mathrm{~h}$. The cells treated with BAI for $24 \mathrm{~h}$. During this study, JuLi $\mathrm{Br}$ recorded images of the cells at 5 min intervals, and confluences were also measured.

Flow cytometric analysis. Approximately $0.5 \times 10^{6}$ cells were suspended in $100 \mu \mathrm{l}$ PBS, and $200 \mu \mathrm{l}$ of $95 \%$ ethanol was added while vortexing. The cells were incubated at $4^{\circ} \mathrm{C}$ for $1 \mathrm{~h}$, washed with PBS, and resuspended in $250 \mu \mathrm{l}$ of $1.12 \%$ sodium citrate buffer ( $\mathrm{pH} 8.4$ ) together with $12.5 \mu \mathrm{g}$ RNase. Incubation was continued at $37^{\circ} \mathrm{C}$ for $30 \mathrm{~min}$. The cellular DNA was then stained by applying $250 \mu \mathrm{l}$ propidium iodide $(50 \mu \mathrm{g} / \mathrm{ml})$ for $30 \mathrm{~min}$ at room temperature. The stained cells were analyzed by a FACScan flow cytometer for relative DNA content based on red fluorescence.
Table I. Primer sequences of miRNA machinery components used in quantitative PCR.

\begin{tabular}{|c|c|c|}
\hline Components & Position & Sequences \\
\hline \multirow[t]{2}{*}{ Bcl-2 } & Forward & 5'-GCCTTCTTTGAGTTCGGTGG-3' \\
\hline & Reverse & 5'-ATCTCCCGGTTGACGCTCT-3' \\
\hline \multirow[t]{2}{*}{ Bcl-xL } & Forward & 5'-GGTCGCATTGTGGCCTTT-3' \\
\hline & Reverse & 5'-TCCTTGTCTACGCTTTCCACG-3' \\
\hline \multirow[t]{2}{*}{$\beta$-actin } & Forward & 5'-CAGCCATGTACGTTGCTATCCAGG-3' \\
\hline & Reverse & 5'- AGGTCCAGACGCAGGATGGCATG-3' \\
\hline
\end{tabular}

DEVDase activity assay. To evaluate caspase-3 activity, cell lysates were prepared after their respective treatment with various drugs. Assays were performed in 96-well microtiter plates by incubating $20 \mu \mathrm{g}$ cell lysates in $100 \mu \mathrm{l}$ reaction buffer [1\% NP-40, 20 mM Tris- $\mathrm{HCl}$ (pH 7.5), $137 \mathrm{mM} \mathrm{NaCl}$, and $10 \%$ glycerol)] containing the caspase 3 substrate (DEVD-pNA) at $5 \mu \mathrm{M}$. Lysates were incubated at $37^{\circ} \mathrm{C}$ for $2 \mathrm{~h}$. Thereafter, the absorbance at $405 \mathrm{~nm}$ was measured with a spectrophotometer.

RNA isolation and quantitative real-time PCR. Total cellular RNA was extracted from tissues using the TRIzol reagent (Molecular Research Center, Inc., Cincinnati, $\mathrm{OH}$, USA). RNA was quantified using Nanodrop 1000 (Thermo Scientific, Wilmington, DE, USA). Each cDNA was synthesized from $2 \mu \mathrm{g}$ of total RNA using M-MLV reverse transcriptase (Promega, Madison, WI, USA) according to the manufacturer's protocol. By using the specific primer pairs described in Table I and SYBR Green Premix (Toyobo, Japan). Quantitative real-time PCR (qPCR) was performed on the LightCycler $^{\circledR} 480$ real-time PCR system (Roche Diagnostics, Mannheim, Germany). $\beta$-actin was used as a housekeeping gene for normalization, and no-template sample was used as a negative control. Then, the qPCR data were analyzed by the $2^{-\Delta \Delta c t}$ method (11).

Determination of the mitochondrial membrane potential by rhodamine 123. Rhodamine 123 (Invitrogen, Molecular Probes, Inc., Eugene, OR, USA) uptake by mitochondria is directly proportional to its membrane potential. Caki cells subjected to $2 \mathrm{~h}$ after treatment were incubated with rhodamine $123(20 \mu \mathrm{M})$ for $10 \mathrm{~min}$ in the dark at $37^{\circ} \mathrm{C}$. The cells were harvested and suspended in PBS. The mitochondrial membrane potential was subsequently analyzed using a flow cytometer (BD Bioscience).

Analysis of mitochondrial cytochrome c release. Approximately $0.3 \times 10^{6}$ Caki cells were harvested, washed once with ice-cold PBS and gently lysed for $2 \mathrm{~min}$ in $80 \mu \mathrm{l}$ ice-cold lysis buffer (250 mM sucrose, $1 \mathrm{mM}$ EDTA, $20 \mathrm{mM}$ Tris- $\mathrm{HCl} \mathrm{pH}$ 7.2, $1 \mathrm{mM}$ DTT, $10 \mathrm{mM} \mathrm{KCl}, 1.5 \mathrm{mM} \mathrm{MgCl}$, $5 \mu \mathrm{g} / \mathrm{ml}$ pepstatin A, $10 \mu \mathrm{g} / \mathrm{ml}$ leupeptin, $2 \mu \mathrm{g} / \mathrm{ml}$ aprotinin). Lysates were centrifuged at $12,000 \mathrm{~g}$ at $4^{\circ} \mathrm{C}$ for $10 \mathrm{~min}$ to obtain the supernatants (cytosolic extracts free of mitochondria) and the pellets (fraction that contains mitochondria). 
A

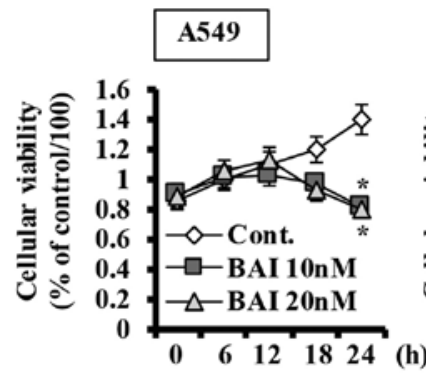

B

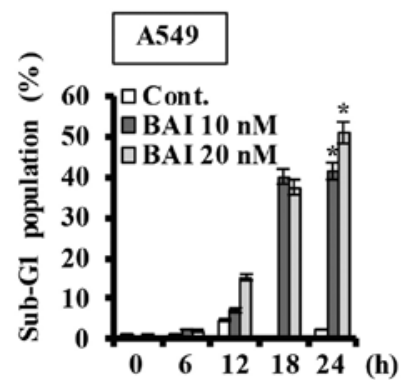

C

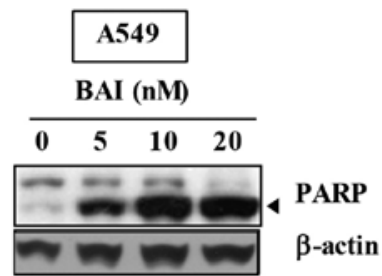

D

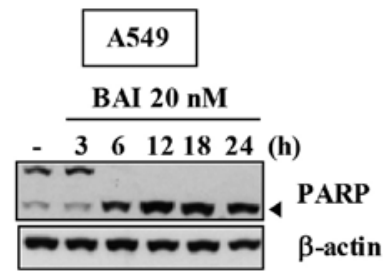

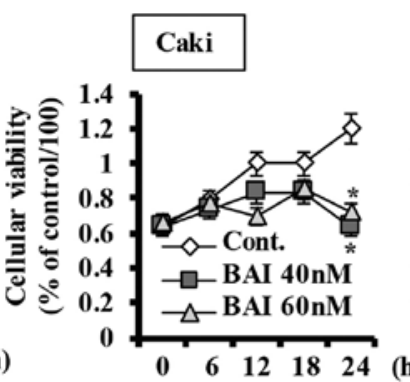
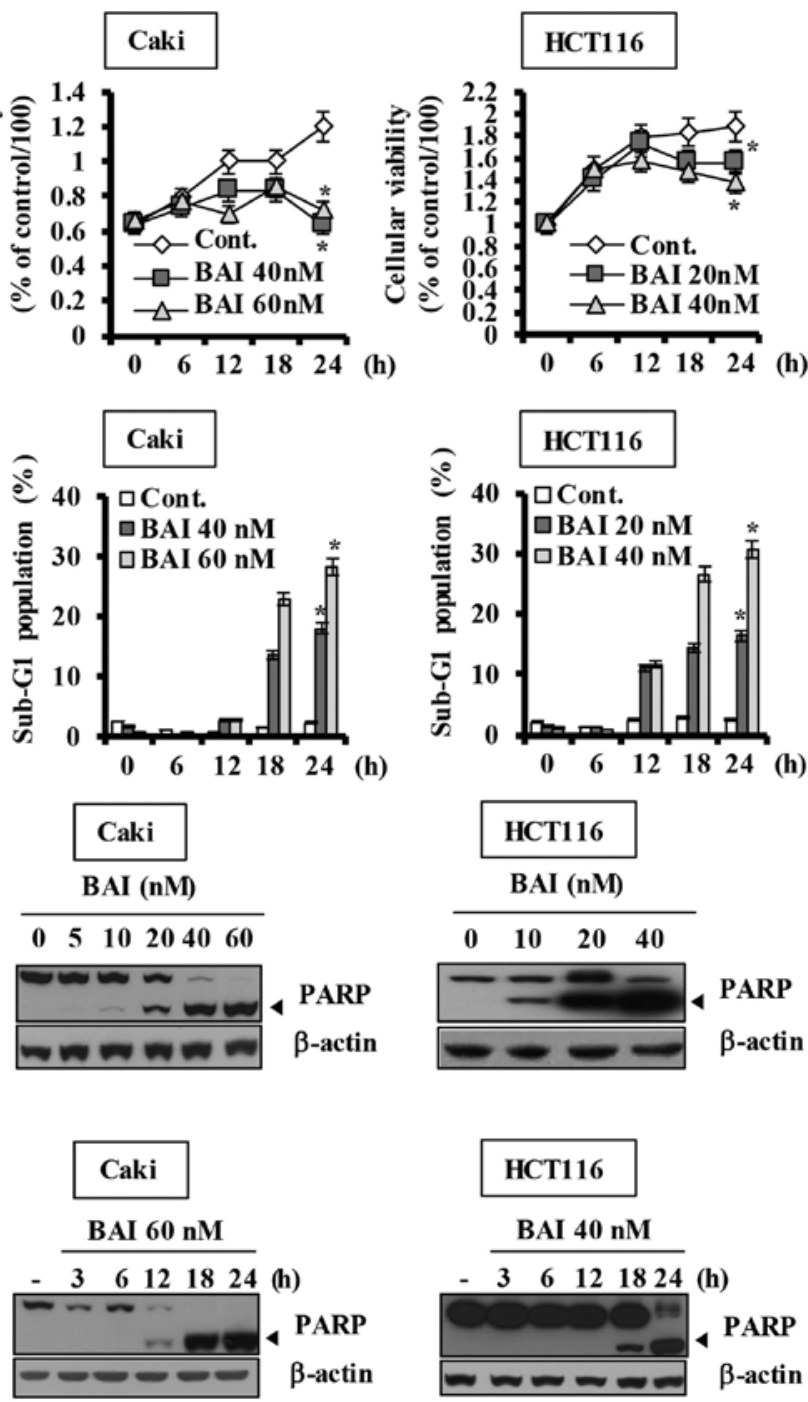

Figure 1. BAI induces apoptosis in a caspase-3-dependent manner. A549, Caki, and HCT116 cells were treated with the indicated concentrations of BAI for the indicated time periods. (A) Cell viability was determined by a live cell movie analyzer, JuLI Br. (B) The sub-G1 fraction (apoptotic cells) was measured by flow cytometry. (C and D) The protein level of PARP was determined by western blot analysis. Cleaved form of PARP is indicated by an arrowhead. The level of $\beta$-actin was used as a loading control. ${ }^{*} \mathrm{P}<0.001$ compared to the control.

Cytosolic protein $(30 \mu \mathrm{g})$ was resolved on $12 \%$ SDS-PAGE and then transferred to nitrocellulose, and probed with specific anti-cytochrome $c$ antibody.

Assay for Bax oligomerization. The cells were suspended by conjugation buffer (PBS with $10 \mathrm{mM}$ EDTA). The cell lysates were incubated with $0.2 \mathrm{mM}$ bismaleimide (Thermo Scientific, Hudson, NH, USA) at room temperature for $1 \mathrm{~h}$ and then extracted by lysis buffer for western blot analysis.

Co-immunoprecipitation assays. Caki cells were exposed to $60 \mathrm{nM}$ BAI for the indicated time periods and cell lysates were prepared in 1X RIPA buffer [20 mM Tris- $\mathrm{HCl}(\mathrm{pH} 7.5)$, $150 \mathrm{mM} \mathrm{NaCl}, 1 \mathrm{mM} \mathrm{Na}{ }_{2}$ EDTA, $1 \% \mathrm{NP}-40,1 \%$ deoxycholate, $2.5 \mathrm{mM}$ sodium pyrophosphate, $1 \mathrm{mM} \beta$-glycerophosphate, $1 \mathrm{mM} \mathrm{Na} \mathrm{VO}_{4}, 1 \mathrm{mg} / \mathrm{ml}$ leupeptin, \#9806, Cell Signaling Technology]. The cells were disrupted by sonication and centrifuged $(13,000 \mathrm{rpm})$ at $4^{\circ} \mathrm{C}$ for $15 \mathrm{~min}$. Cell lysates were then subjected to immunoprecipitation with an anti-Bcl-xL antibody. Protein G PLUS-agarose were added and then the cell lysates were rotated at $4^{\circ} \mathrm{C}$ for $2 \mathrm{~h}$. The cell lysates were centrifuged $(13,000 \mathrm{rpm})$ at $4^{\circ} \mathrm{C}$ for $10 \mathrm{~min}$. The presence of p53 and PUMA in the anti-Bcl-xL immunoprecipitate (IPs) and lysates was then evaluated by immunoblot analysis using the specific antibodies.

Statistical analysis. The data were analyzed using a one-way ANOVA followed by post-hoc comparisons (Student-NewmanKeuls) using the Statistical Package for Social Sciences version 22.0 (SPSS Inc., Chicago, IL, USA).

\section{Results}

BAI has anti-proliferative effects on various human cancer cells. Previous reports demonstrated that BAI induces apoptosis of various human cancer cell lines. To investigate the anticancer effects of BAI in detail, we first analyzed the growth inhibitory effect of BAI in the same human cancer cell lines using an automated cell counter. As shown in Fig. 1A, BAI markedly inhibited proliferation of various human 
A
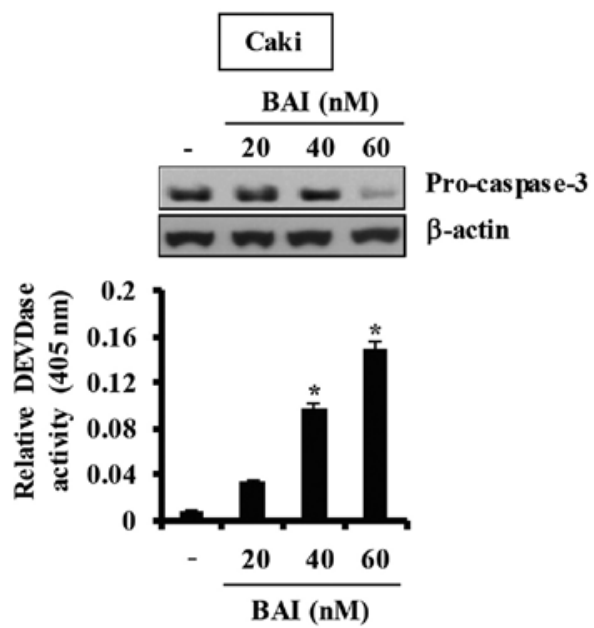

B

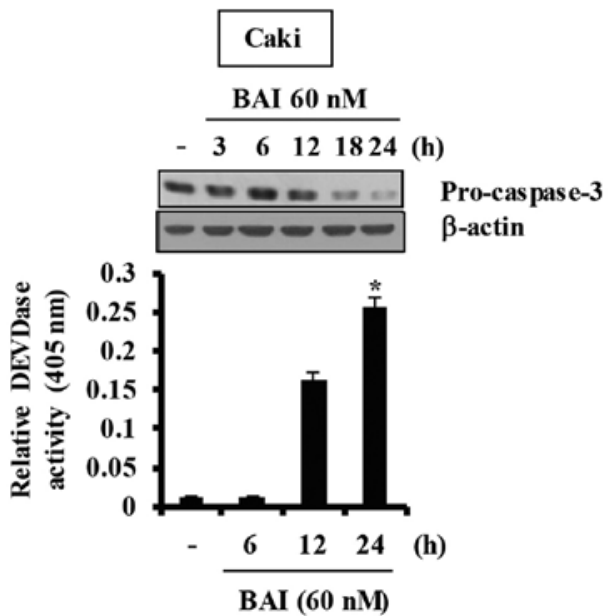

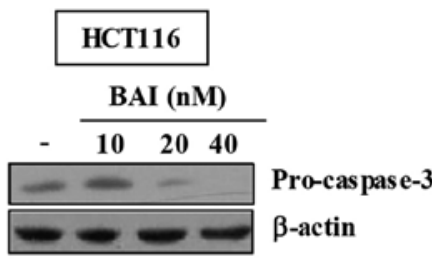
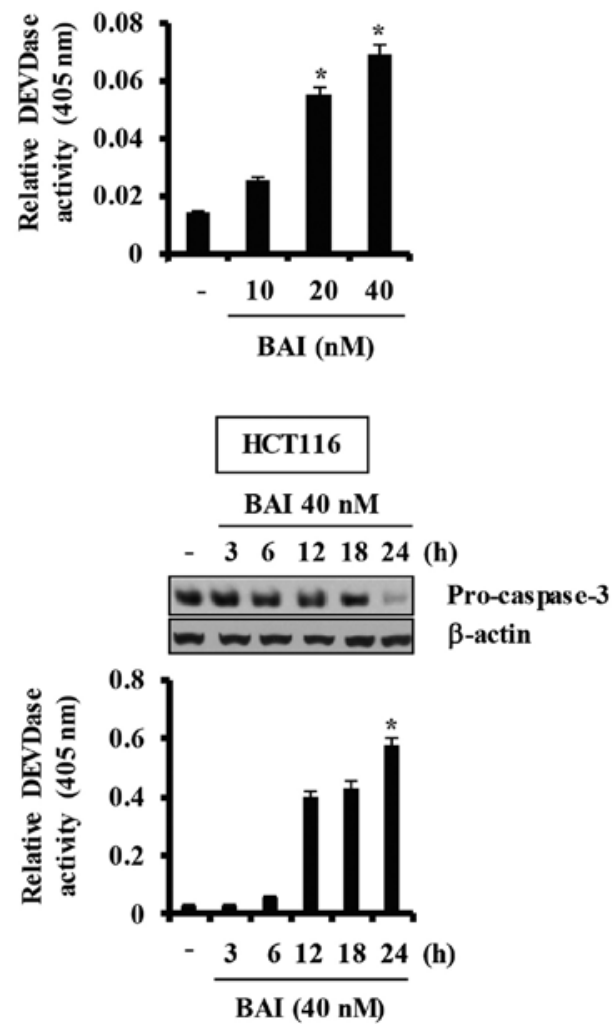

Figure 2. BAI induces caspase-3 activation in various human cancer cells. (A) Caki and HCT116 cells were treated with the indicated concentrations of BAI for $24 \mathrm{~h}$. The protein level of pro-caspase-3 was determined by western blot analysis. The level of $\beta$-actin was used as a protein loading control (upper panel). Caspase activities were determined with colorimetric assays using caspase-3 (DEVDase) assay kits (lower panel). (B) Caki and HCT116 cells were treated with the indicated concentrations of BAI for the indicated time periods. The protein level of pro-caspase- 3 was determined by western blot analysis. The level of $\beta$-actin was used as a protein loading control (upper panel). Caspase activities were determined with colorimetric assays using caspase-3 (DEVDase) assay kits (lower panel). $\mathrm{P}<0.001$ compared to the control.

cancer cell lines dose- and time-dependently. To examine the apoptotic effects of BAI, the cells were next treated with various concentrations of BAI for the indicated times and then apoptosis was assessed using flow cytometry to detect hypodiploid cell populations. Treatment of the cells with BAI resulted in a remarkably increased accumulation of cells in the sub-G1 population and an increase in PARP cleavage in a dose-dependent manner (Fig. 1B and C) and a time-dependent manner (Fig. 1B and D). Furthermore, BAI induced caspasedependent apoptosis in various cancer cell lines, including A549, HCT116, and Caki, in a dose- and time-dependent manner (Fig. 2). Taken together, these data demonstrate that BAI induces caspase-3-dependent apoptosis.

The roles of specific apoptosis-related pathways in BAI-induced apoptosis: MAPKase pathways or ROS generation. Mitogenactivated protein kinases (MAPKs) are key participants in cell proliferation, survival, and differentiation $(12,13)$. To explore the signaling events regulated during BAI-induced apoptosis, we used specific inhibitors. Our results showed that specific
MAPK inhibitors (PD, MEK inhibitor; SP, JNK inhibitor; SB, p38 MAPK inhibitor) did not affect BAI-induced apoptosis in Caki and A549 cells (Fig. 3A). Reactive oxygen species (ROS), natural byproducts of the normal metabolism of oxygen, play a crucial role in apoptosis under both physiologic and pathologic processes (14). Therefore, we investigated whether ROS generation is involved in BAI-induced apoptosis in Caki cells. As shown in Fig. 3B, BAI-induced apoptosis was not attenuated by pretreatment with $\mathrm{N}$-acetylcysteine (NAC) or glutathione (GEE). These data indicate that BAI-induced apoptosis is not associated with MAPK pathways or ROS generation.

$B A I$ reduces mitochondrial membrane potential (MMP) and induces Bax activation. In general, apoptosis induction is correlated with, and probably mediated by, perturbations of mitochondrial function, a manifestation of which is the dissipation of the transmembrane potential $\left(\Delta \Psi_{\mathrm{m}}\right)$. Therefore, we evaluated $\Delta \Psi_{\mathrm{m}}$ during apoptosis induction in BAI-treated human cancer cells. As shown in Fig. 4A, treatment with 
A

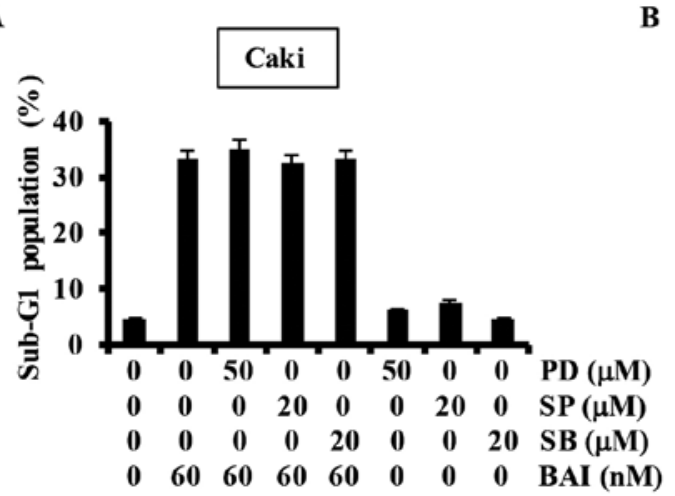

B

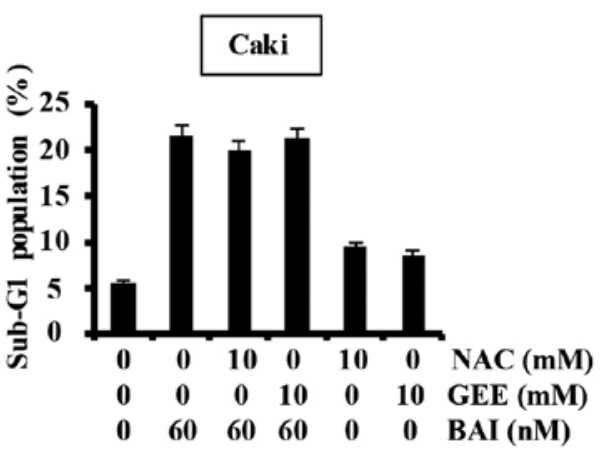

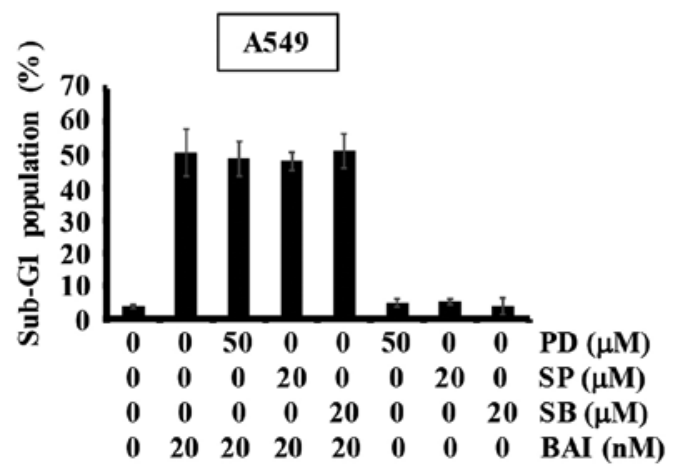

Figure 3. BAI-induced apoptosis is not associated with MAPKase pathway or ROS generation. (A) Caki and A549 cells were treated with the indicated concentrations of MEK or JNK or p38 MAPK inhibitors or solvent for 30 min before treatment with the indicated concentrations of BAI for $24 \mathrm{~h}$ and then sub-G1 fraction was measured by flow cytometry. (B) Caki cells were treated with BAI in the presence or absence of $10 \mathrm{mM} \mathrm{NAC}$ and $10 \mathrm{mM}$ GEE for $24 \mathrm{~h}$. The sub-G1 fraction was measured by flow cytometry.

A

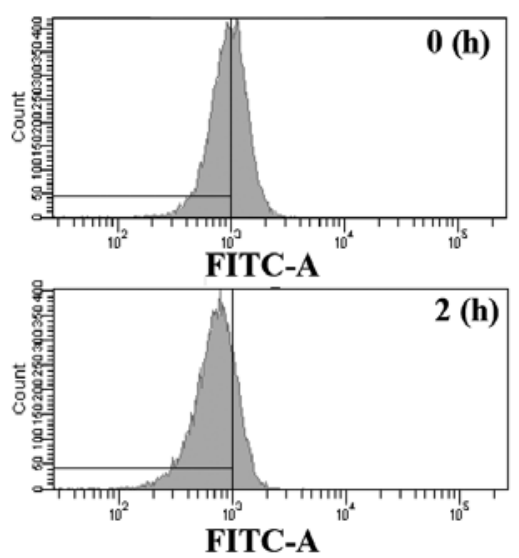

B

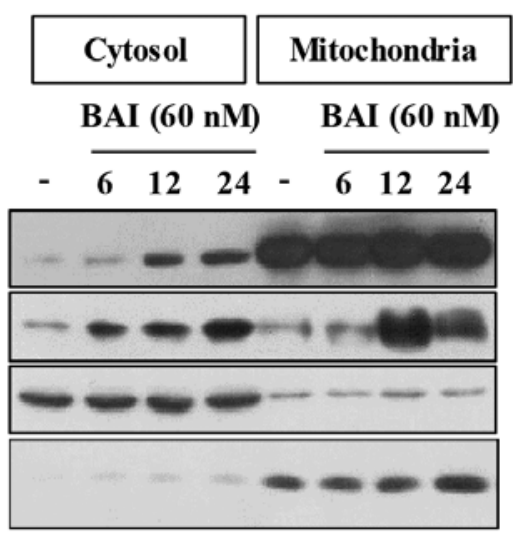

C

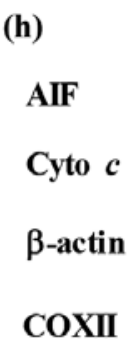

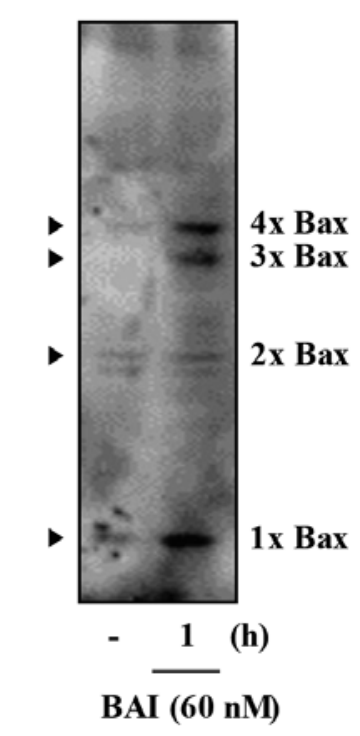

Figure 4. BAI induces a reduction of mitochondrial transmembrane $\left(\Delta \Psi_{\mathrm{m}}\right)$, release of cytochrome $c$ and AIF from mitochondria, and Bax activation. (A) Caki cells were treated with $60 \mathrm{nM}$ BAI for various time periods, and loaded with a fluorescent dye, rhodamine 123 . Rhodamine 123 fluorescence intensity was measured by flow cytometry. (B) Cytosolic extracts were prepared as described in Materials and methods. The protein levels of AIF and cytochrome $c$ were determined by western blot analysis. The level of $\beta$-actin was used as a loading control. The level of QPs2 was used as no mitochondrial contamination in the cytosolic preparation. (C) For Bax oligomerization assay, Caki cells were treated $60 \mathrm{nM} \mathrm{BAI}$ for $1 \mathrm{~h}$. After treatment, Bax monomers and oligomers were detected by western blot analysis. Oligomerization of Bax is indicated by an arrowhead.

BAI markedly decreased $\Delta \Psi_{\mathrm{m}}$ in Caki cells. Mitochondria mediates apoptosis by releasing apoptogenic effectors such as cytochrome $c$ and apoptosis-inducing factor (AIF) $(15,16)$. As shown in Fig. 4B, BAI remarkably induced time-dependent release of cytochrome $c$ and AIF into the cytoplasm in Caki cells. Several lines of evidence strongly support the notion 
A

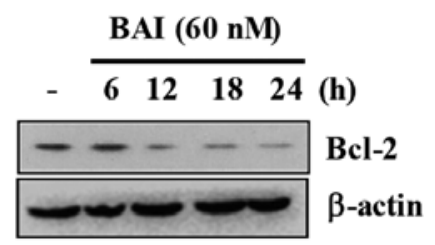

C

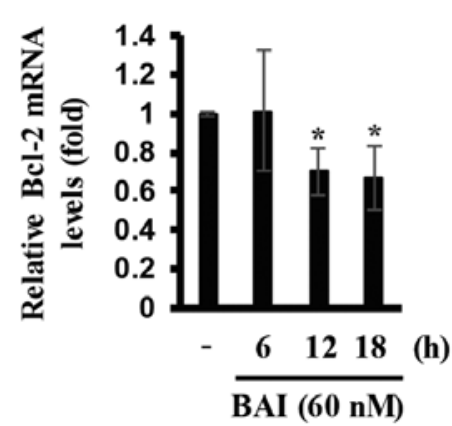

B
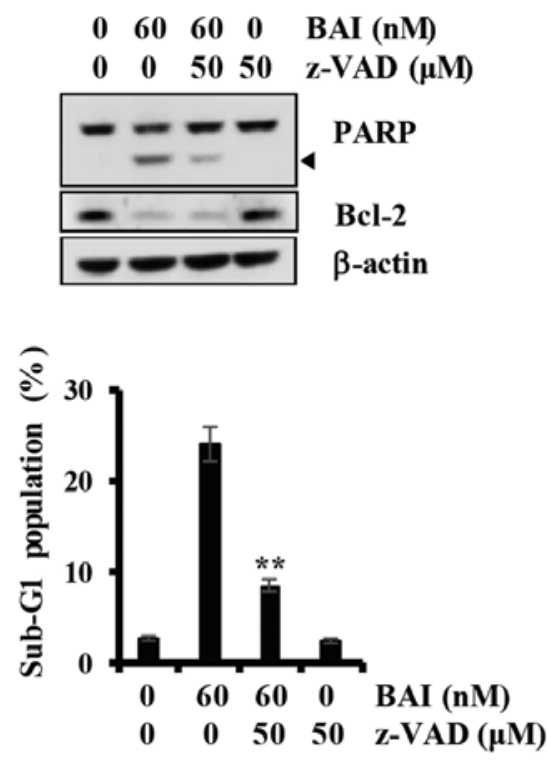

D
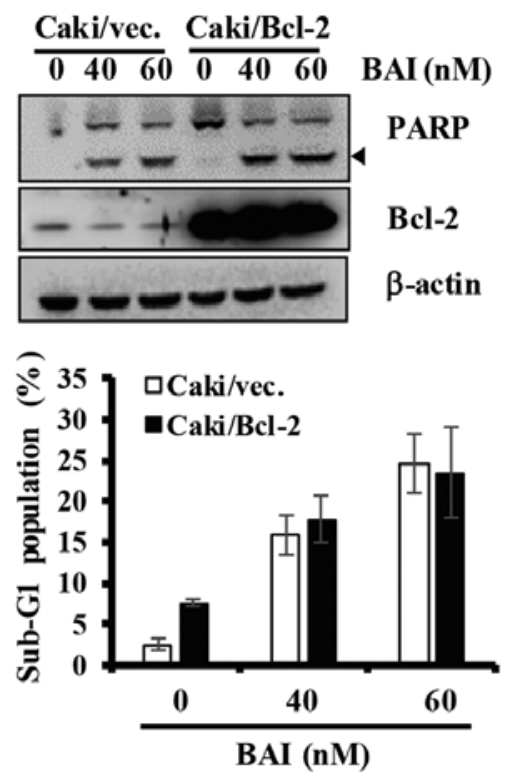

Figure 5. BAI-induced apoptosis is not attenuated by Bcl-2 overexpression in Caki cells. (A) Caki cells were treated with 60 nM BAI for the indicated time periods. The protein level of Bcl-2 was determined by western blot analysis. $\beta$-actin was used as a protein loading control. (B) Caki cells were pretreated with z-VAD-fmk or vehicle for $1 \mathrm{~h}$ and then treated with $60 \mathrm{nM}$ BAI for $24 \mathrm{~h}$. The protein levels of Bcl-2 were determined by western blot analysis. The level of $\beta$-actin was used as a protein loading control (upper panel). The sub-G1 fraction was measured by flow cytometry (lower panel). (C) Caki cells were treated with $60 \mathrm{nM}$ BAI for the indicated time periods. Each mRNA expression was determined using RT and qPCR. (D) Vector cells (Caki/vec.), Bcl-2-overexpressed cells (Caki/Bcl-2) were treated with the indicated concentrations of BAI for $24 \mathrm{~h}$. The protein levels of PARP and Bcl-2 were determined by western blot analysis. The level of $\beta$-actin was used as a protein loading control (upper panel). The sub-G1 fraction was measured by flow cytometry (lower panel). Cleaved form of PAPP is indicated by an arrowhead. ${ }^{*} \mathrm{P}<0.001$ compared to the control. ${ }^{* *} \mathrm{P}<0.001$ compared to the treatment of BAI.

that activation of the pro-apoptotic $\mathrm{Bcl}-2$ protein, Bax, plays a critical role in apoptosis by changes of MMP levels and release of cytochrome $c$ (17). Therefore, we next evaluated the effect of BAI on Bax activation. As shown in Fig. 4C, BAI markedly promoted Bax oligomerization. Taken together, these results suggest that BAI induces loss of MMP levels and release of cytochrome $c$ through activation of Bax.

Downregulation of Bcl-2 is not associated with BAI-induced apoptosis in Caki cells. We next determined the effect of BAI on Bcl-2 regulation in Caki cells. As shown in Fig. 5A, data from kinetic analysis showed that treatments with BAI for various time-points (6-24 h) led to a marked downregulation of Bcl-2. To identify the Bcl-2 regulating mechanisms by BAI, we treated Caki cells with or without BAI in the presence or absence of z-VAD-fmk, a pan-caspase inhibitor, for $24 \mathrm{~h}$, and then measured sub-G1 populations and the cellular levels of PARP, Bcl-2, and $\beta$-actin by FACS and western blot analysis, respectively. BAI induced cleavage of PARP and increased the population of Caki cells in the sub-G1 phase, which were largely suppressed by pre-treatment with z-VAD-fmk (Fig. 5B). However, BAI-induced downregulation of Bcl-2 was not blocked by pre-treatment with z-VAD-fmk, suggesting that the downregulation of $\mathrm{Bcl}-2$ protein is not involved in caspase activity (Fig. 5B). Therefore, we next investigated the effect of BAI on the transcriptional regulation of Bcl-2 by RT-qPCR analysis. As shown in Fig. 5C, BAI reduced levels of Bcl-2 transcripts in a time-dependent manner. To further investigate the role of Bcl-2 in BAI-induced apoptosis, we used Caki renal carcinoma cells engineered for overexpression of Bcl-2. As shown in Fig. 5D, overexpression of Bcl-2 could not attenuate the apoptosis induced by BAI. Collectively, these results indicate that downregulation of $\mathrm{Bcl}-2$ is not associated with BAI-induced apoptosis in Caki cells.

BAI modulates the expression of Bcl-xL and the interactions among p53 and Bcl-2 family proteins in human cancer cells. $\mathrm{Bcl}-\mathrm{xL}$ is a widely studied factor of resistance to cytotoxic anticancer agents. We first examined whether Bcl-xL is associated with BAI-induced apoptosis, cancer cells were treated with BAI at different times. As shown in Fig. 6A, BAI treatment of cancer cells for various time-points resulted in markedly decreased expression levels of Bcl-xL in A549 and Caki cells. We explored the possible link between loss of Bcl-xL protein and activation of caspases in BAI-treated A549 cells. As shown in Fig. 6B, pretreatment with z-VAD-fmk had no effect on the reduction of Bcl-xL protein by BAI, implying that the BAI-induced downregulation of Bcl-xL protein is not associated with caspase activity. This led us to investigate the effect of BAI on transcriptional regulation of Bcl-xL. Notably, results of RT-qPCR analysis, as shown in Fig. 6C, demonstrated a marked reduction of Bcl-xL transcripts in BAI-treated cells, suggesting that BAI downregulates Bcl-xL at the transcriptional levels. To evaluate the functional significance of BAI-induced Bcl-xL downregulation, we transfected A549 cells with siRNA targeting Bcl-xL mRNA and treated cells with or without BAI for $24 \mathrm{~h}$. The concentrations of BAI were sub-cytotoxic in comparison with the results of previous experiments. Immunoblot analysis confirmed that transfection with Bcl-xL siRNA resulted in suppression of $\mathrm{Bcl}-\mathrm{xL}$ 
A

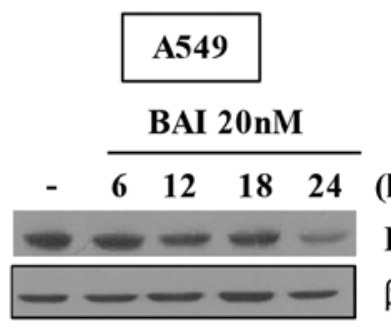

C

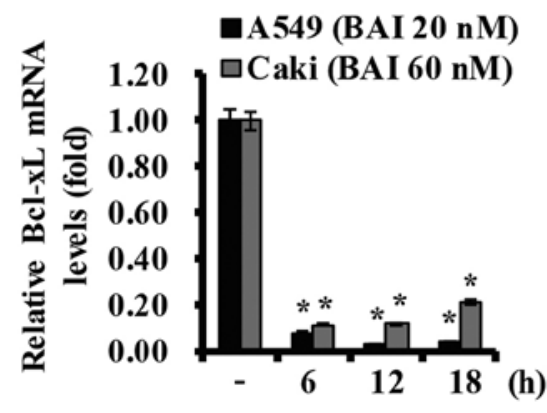

$\mathbf{E}$

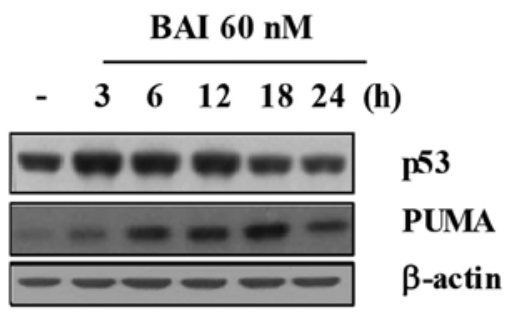

(h)

Bcl-xL

$\beta-$ actin

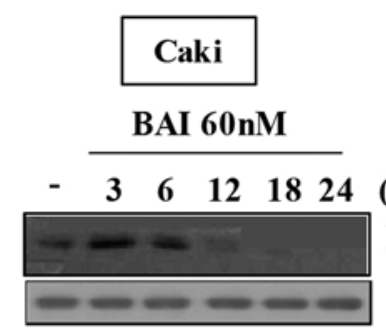

(h)

Bcl-xL $\beta-a c t i n$
B

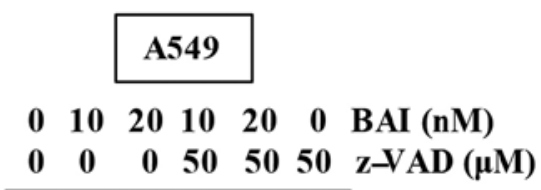

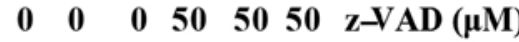

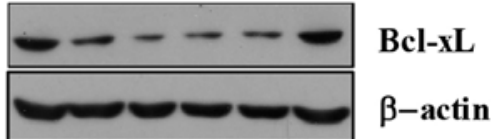

D

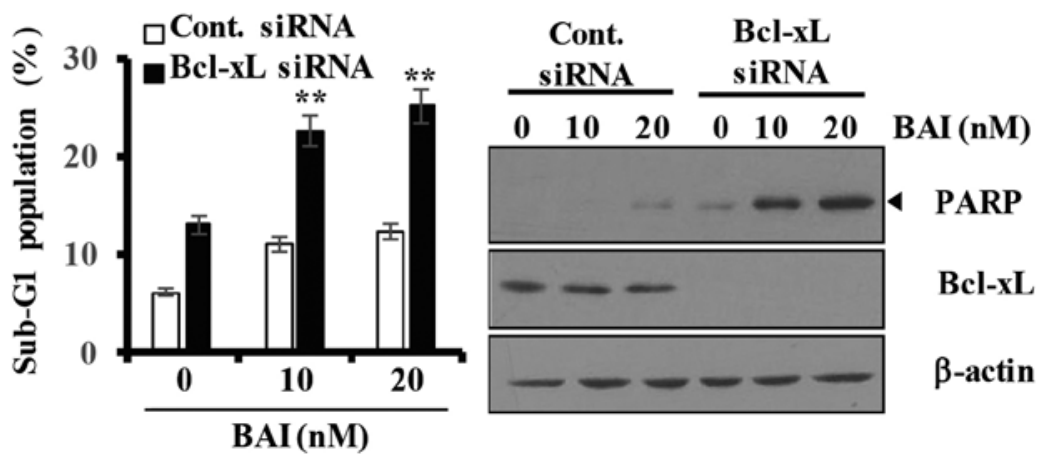

$\mathbf{F}$

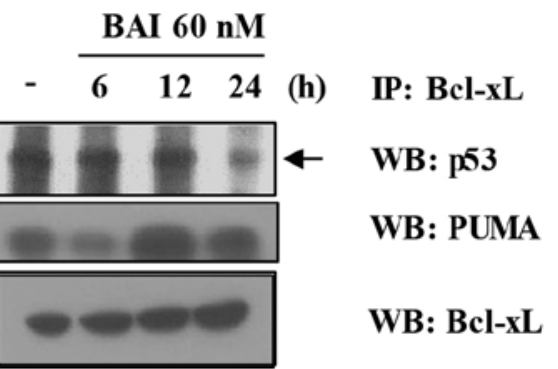

G
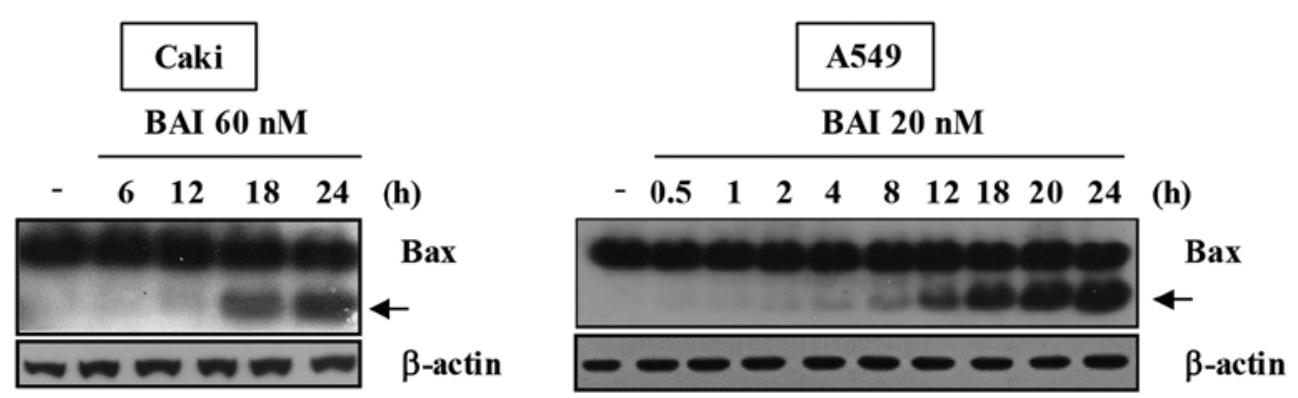

Figure 6. BAI modulates the expression of Bcl-xL and the interactions among p53 and Bcl-2 family proteins in human cancer cells. (A) A549 and Caki cells were treated with the indicated concentrations of BAI for the indicated time periods. The protein level of Bcl-xL was determined by western blot analysis. $\beta$-actin was used as a protein loading control. (B) A549 cells were pretreated with z-VAD-fmk or vehicle for $1 \mathrm{~h}$ and then treated with BAI (10 and $20 \mathrm{nM}$ ) for $24 \mathrm{~h}$. The protein levels of Bcl-xL were determined by western blot analysis. The level of $\beta$-actin was used as a protein loading control. (C) A549 and Caki cells were treated with the indicated concentrations of BAI for the indicated time periods. Each mRNA expression was determined using RT and qPCR. (D) Caki cells were transfected with Bal-xL siRNA or GFP siRNA. Thirty hours after transfection, cells were treated with BAI (10 and $20 \mathrm{nM})$ for $24 \mathrm{~h}$. The sub-G1 fraction was measured by flow cytometry (left panel). The protein levels of PARP and Bcl-2 were determined by western blot analysis. The level of $\beta$-actin was used as a protein loading control (right panel). (E) Caki cells were treated with $60 \mathrm{nM}$ BAI for the indicated time periods. The protein levels of p53 and PUMA were determined by western blot analysis. The level of $\beta$-actin was used as a protein loading control. (F) Caki cells were treated with $60 \mathrm{nM}$ BAI for the indicated time periods. The lysates were performed by immunoprecipitation (IP) with Bcl-xL, and then the levels of p53, PUMA, and Bcl-xL were determined by western blot analysis. Cleaved form of PAPP is indicated by an arrowhead. p53 binding to Bcl-xL is indicated by an arrow. (G) A549 and Caki cells were treated with BAI for the indicated time periods. The protein level of Bax was determined by western blot analysis. Cleaved form of Bax is indicated by an arrow. The level of $\beta$-actin was used as a loading control. " $\mathrm{P}<0.001$ compared to the control. ${ }^{* *} \mathrm{P}<0.001$ compared to the GFP siRNA transfected Caki cells treated with BAI.

expression in A549 cells compared with cells transfected with control GFP siRNA (Fig. 6D). Notably, the BAI-induced accumulation of sub-G1 phase was markedly increased in cells transfected with Bcl-xL siRNA as compared with control 
siRNA-transfected cells (Fig. 6D). In addition, the expression of cleaved PARP was induced only in cells transfected with Bcl-xL siRNA (Fig. 6D).

Bcl-2 family members regulate survival/death decisions through a network of interactions among the pro-survival member Bcl-xL, the pro-apoptotic member PUMA, and p53 $(9,10,18)$. We next investigated whether BAI affects the expression levels of $\mathrm{p} 53$ and PUMA proteins in cancer cells. As shown in Fig. 6E, Caki cells treated with BAI showed upregulation of $\mathrm{p} 53$ and PUMA in a time-dependent manner. We then determined whether BAI modulates the interactions between specific Bcl-2 families in Caki cells using co-immunoprecipitation assays. As shown in Fig. 6F, BAI not only efficiently disrupted the Bcl-xL/p53 interaction but also induced the binding between PUMA and Bcl-xL in Caki cells in a time-dependent manner. Additionally, A549 and Caki cells treated with BAI showed induction of Bax cleavage in a time dependent manner (Fig. 6G). Taken together, these results suggest that downregulation of $\mathrm{Bcl}-\mathrm{xL}$ protein is importantly associated with the BAI-induced apoptosis and that BAI modulates interactions among $\mathrm{p} 53$ and $\mathrm{Bcl}-2$ family proteins in human cancer cells.

\section{Discussion}

Until recently, targeted cancer therapy was widely accepted as an effective means for cancer therapeutic strategies (19). However, recent reports have shown that intratumoral heterogeneity plays an important role in tumor adaptation and therapeutic failure (20). For this reason, appropriate validation and balanced modulation of multiple targets have been attractive therapeutic strategies in treating cancer. Recent studies reported the synthesis and anticancer effects of the novel cyclin-dependent kinase inhibitor BAI (1-4). BAI was shown to exhibit various apoptotic effects, including caspase activation, inactivation of Akt (2), and sensitizing effect on farnesyltransferase inhibitor, LB42708-mediated apoptosis through the downregulation of Bcl-2 and c-FLIP (L) (4). In this study, we further investigated the apoptotic mechanisms of BAI in the human renal cell carcinoma Caki cell line and human non-small cell lung cancer A549 cell line.

Among the apoptosis-related pathways, ROS generation and MAPK pathways have been known to modulate apoptosis in cancer. It is a promising cancer therapeutic strategy to eliminate cancer cells by regulating oxidative stress-mediated apoptosis induced by cytotoxic drugs (21). Furthermore, MAPK pathways play an important role in modulating survival and apoptosis of cancer cells (22). Our data using specific inhibitors on ROS generation or MAPK pathways showed that these inhibitors did not influence BAI-induced apoptosis in Caki cells, indicating that ROS generation and MAPK pathways are not involved in BAI-induced apoptosis.

Anti-apoptotic Bcl-2 family proteins such as Bcl-xL are frequently overexpressed in cancers (23). Downregulation of cell survival proteins may render cancer cells sensitive to anticancer agents. A previous study showed that BAI downregulated the expression levels of XIAP and Mcl-1 (L) proteins (2). However, downregulations of XIAP and Mcl-1 (L) proteins were not associated with BAI-induced apoptosis (2). On the other hand, BAI inhibited activation of p-Akt, and the inac- tivation of p-Akt contributed to BAI-facilitated PI3K/Akt inhibitor LY294002-induced apoptosis (2). In this study, we investigated the role of anti-apoptotic Bcl-2 family proteins, such as Bcl-2 and Bcl-xL in BAI-induced apoptosis. Our data showed that BAI downregulated Bcl-2 expression at the transcriptional levels, but overexpression of $\mathrm{Bcl}-2$ could not block BAI-induced apoptosis. These results suggest that downregulation of $\mathrm{Bcl}-2$ is not involved in BAI-induced apoptosis in Caki cells. Bcl-2 proteins, such as Bcl-2, are related to chemoresistance in a variety of human cancers $(24,25)$. Therefore, targeting Bcl-2 members represents a promising anticancer strategy (26). Notably, our data showed that BAI could induce apoptosis in Bcl-2-overexpressing Caki cells. These results suggest that BAI could overcome the increased activity of Bcl-2, suggesting that BAI may be a potentially useful anticancer agent against Bcl-2-overexpressing malignancies. We also found that BAI downregulated $\mathrm{Bcl}-\mathrm{xL}$ at the transcriptional level and that Bcl-xL siRNA increased the sensitivity of BAI in the human cancer cells, suggesting that downregulation of Bcl-xL plays an important role in BAI-induced apoptosis.

Following DNA damage, nuclear or cytoplasmic accumulation of the tumor suppressor p53 is an important mechanism in apoptosis (27). Cytoplasmic p53 is sequestered by antiapoptotic Bcl-2 family proteins, such as Bcl-xL $(18,27)$. The BH3-only protein PUMA, induced by nuclear p53, mediates cytosolic pro-apoptotic p53 function (9). When DNA damage induces apoptosis, cytoplasmic p53 is released from the complex with Bcl-xL and can directly activate Bax, subsequently promoting apoptosis via mitochondrial outer membrane permeabilization (28). Based on the DNA damagep53-PUMA-Bcl-xL-mediated apoptotic signaling pathway, we hypothesized that BAI-induced apoptosis follows this apoptotic signaling pathway. We previously reported that BAI induces DNA fragmentation (2). In this study, BAI upregulated the expression levels of p53 and PUMA in a time-dependent manner. Furthermore, we demonstrated that BAI disrupts the interaction between p53 and Bcl-xL, and induces PUMA binding to Bcl-xL in Caki cells. Further studies are required to elucidate the precise regulatory mechanisms underlying the interactions among p53 and Bcl-2 family proteins (PUMA and $\mathrm{Bcl}-\mathrm{xL}$ ) in BAI-induced apoptosis, however, our results demonstrate that $\mathrm{p} 53$ and $\mathrm{Bcl}-2$ family proteins play important roles in BAI-induced apoptosis of human cancer cells. Additionally, we found that upregulation of p53 was followed by that of PUMA in BAI-treated cancer cells (Fig. 6E). PUMA is a mediator of p53-induced apoptosis $(29,30)$. Therefore, it is required to investigate whether p53 or PUMA play an important role in BAI-induced apoptosis.

Bax cleavage is a well-known and important phenomenon in caspase-dependent apoptosis (31-33). Our findings demonstrated that BAI induces Bax cleavage and promotes Bax oligomerization.

Mitochondria play an essential role in apoptosis by releasing apoptogenic effectors such as AIF and cytochrome $c(15,34)$. We found that BAI markedly decreased MMP in human cancer cells and induced a marked release of cytochrome $c$ and AIF into the cytoplasm. Given that release of AIF and cytochrome $c$ from the mitochondria to the cytoplasm triggers activation of the caspase-3 pathway (35), it is likely that the 
release of AIF and cytochrome $c$ induced by BAI is implicated in caspase-dependent apoptosis in human cancer cells.

Together our data show that BAI induces apoptosis in various cancer cells through loss of MMP, activation of Bax, downregulation of $\mathrm{Bcl}-\mathrm{xL}$, and regulation of interactions among p53, PUMA, and Bcl-xL. These findings support the idea that BAI may be useful for development as an attractive multi-target drug against cancer.

\section{Acknowledgements}

This study was supported by the Bisa Research Grant of Keimyung University in 2012.

\section{References}

1. Lee J, Choi H, Kim KH, Jeong S, Park JW, Baek CS and Lee SH: Synthesis and biological evaluation of 3,5-diaminoindazoles as cyclin-dependent kinase inhibitors. Bioorg Med Chem Lett 18: 2292-2295, 2008.

2. Kim S, Lee J, Jang BC, Kwon TK and Park JW: BAI, a novel cyclin-dependent kinase inhibitor induces apoptosis in A549 cells through activation of caspases and inactivation of Akt. J Cell Biochem 114: 282-293, 2013.

3. Shin HC, Song DW, Baek WK, Lee SR, Kwon TK, Lee J, Park SH, Jang BC and Park JW: Anticancer activity and differentially expressed genes in head and neck cancer cells treated with a novel cyclin-dependent kinase inhibitor. Chemotherapy 55: 353-362, 2009.

4. Jang JH, Cho YC, Kim KH, Lee KS, Lee J, Kim DE, Park JS, Jang BC, Kim S, Kwon TK, et al: BAI, a novel Cdk inhibitor, enhances farnesyltransferase inhibitor LB42708-mediated apoptosis in renal carcinoma cells through the downregulation of Bcl-2 and c-FLIP (L). Int J Oncol 45: 1680-1690, 2014.

5. Jacobson MD, Weil M and Raff MC: Programmed cell death in animal development. Cell 88: 347-354, 1997.

6. Thompson CB: Apoptosis in the pathogenesis and treatment of disease. Science 267: 1456-1462, 1995.

7. Green DR and Llambi F: Cell death signaling. Cold Spring Harb Perspect Biol 7: 7, 2015.

8. Kroemer G: The proto-oncogene $\mathrm{Bcl}-2$ and its role in regulating apoptosis. Nat Med 3: 614-620, 1997.

9. Follis AV, Chipuk JE, Fisher JC, Yun MK, Grace CR, Nourse A, Baran K, Ou L, Min L, White SW, et al: PUMA binding induces partial unfolding within BCL-xL to disrupt p53 binding and promote apoptosis. Nat Chem Biol 9: 163-168, 2013.

10. Yu J, Wang Z, Kinzler KW, Vogelstein B and Zhang L: PUMA mediates the apoptotic response to $\mathrm{p} 53$ in colorectal cancer cells. Proc Natl Acad Sci USA 100: 1931-1936, 2003.

11. Schmittgen TD and Livak KJ: Analyzing real-time PCR data by the comparative C(T) method. Nat Protoc 3: 1101-1108, 2008.

12. Graves JD, Campbell JS and Krebs EG: Protein serine/threonine kinases of the MAPK cascade. Ann NY Acad Sci 766 (1 Receptor Acti): 320-343, 1995.

13. Low HB and Zhang Y: Regulatory roles of MAPK phosphatases in cancer. Immune Netw 16: 85-98, 2016.

14. Simon HU, Haj-Yehia A and Levi-Schaffer F: Role of reactive oxygen species (ROS) in apoptosis induction. Apoptosis 5: 415-418, 2000

15. Le Bras M, Rouy I and Brenner C: The modulation of interorganelle cross-talk to control apoptosis. Med Chem 2: 1-12, 2006.

16. Li P, Nijhawan D, Budihardjo I, Srinivasula SM, Ahmad M, Alnemri ES and Wang X: Cytochrome $c$ and dATP-dependent formation of Apaf-1/caspase-9 complex initiates an apoptotic protease cascade. Cell 91: 479-489, 1997.
17. Wei MC, Zong WX, Cheng EH, Lindsten T, Panoutsakopoulou V, Ross AJ, Roth KA, MacGregor GR, Thompson CB and Korsmeyer SJ: Proapoptotic BAX and BAK: A requisite gateway to mitochondrial dysfunction and death. Science 292: 727-730, 2001.

18. Chipuk JE, Bouchier-Hayes L, Kuwana T, Newmeyer DD and Green DR: PUMA couples the nuclear and cytoplasmic proapoptotic function of p53. Science 309: 1732-1735, 2005.

19. Sawyers C: Targeted cancer therapy. Nature 432: 294-297, 2004.

20. Gerlinger M, Rowan AJ, Horswell S, Larkin J, Endesfelder D, Gronroos E, Martinez P, Matthews N, Stewart A, Tarpey P, et al: Intratumor heterogeneity and branched evolution revealed by multiregion sequencing. N Engl J Med 366: 883-892, 2012.

21. Ivanova D, Bakalova R, Lazarova D, Gadjeva V and Zhelev Z: The impact of reactive oxygen species on anticancer therapeutic strategies. Adv Clin Exp Med 22: 899-908, 2013.

22. Xia Z, Dickens M, Raingeaud J, Davis RJ and Greenberg ME: Opposing effects of ERK and JNK-p38 MAP kinases on apoptosis. Science 270: 1326-1331, 1995.

23. Walensky LD: BCL-2 in the crosshairs: Tipping the balance of life and death. Cell Death Differ 13: 1339-1350, 2006.

24. Johnstone RW, Ruefli AA and Lowe SW: Apoptosis: A link between cancer genetics and chemotherapy. Cell 108: 153-164, 2002.

25. Fernandez-Luna JL: Regulation of pro-apoptotic BH3-only proteins and its contribution to cancer progression and chemoresistance. Cell Signal 20: 1921-1926, 2008.

26. Azmi AS, Wang Z, Philip PA, Mohammad RM and Sarkar FH: Emerging Bcl-2 inhibitors for the treatment of cancer. Expert Opin Emerg Drugs 16: 59-70, 2011.

27. Green DR and Kroemer G: Cytoplasmic functions of the tumour suppressor p53. Nature 458: 1127-1130, 2009.

28. Chipuk JE, Kuwana T, Bouchier-Hayes L, Droin NM, Newmeyer DD, Schuler M and Green DR: Direct activation of Bax by $\mathrm{p} 53$ mediates mitochondrial membrane permeabilization and apoptosis. Science 303: 1010-1014, 2004.

29. Hemann MT, Zilfou JT, Zhao Z, Burgess DJ, Hannon GJ and Lowe SW: Suppression of tumorigenesis by the p53 target PUMA. Proc Natl Acad Sci USA 101: 9333-9338, 2004.

30. Jeffers JR, Parganas E, Lee Y, Yang C, Wang J, Brennan J, MacLean KH, Han J, Chittenden T, Ihle JN, et al: Puma is an essential mediator of p53-dependent and -independent apoptotic pathways. Cancer Cell 4: 321-328, 2003.

31. Yanase N, Ohshima K, Ikegami H and Mizuguchi J: Cytochrome $c$ release, mitochondrial membrane depolarization, caspase-3 activation, and Bax-alpha cleavage during IFN-alpha-induced apoptosis in Daudi B lymphoma cells. J Interferon Cytokine Res 20: $1121-1129,2000$

32. Kim YH, Shin HC, Song DW, Lee SH, Furumai T, Park JW and Kwon TK: Arisostatins A induces apoptosis through the activation of caspase- 3 and reactive oxygen species generation in AMC-HN-4 cells. Biochem Biophys Res Commun 309: 449-456, 2003.

33. Yeo JK, Cha SD, Cho CH, Kim SP, Cho JW, Baek WK, Suh MH, Kwon TK, Park JW and Suh SI: Se-methylselenocysteine induces apoptosis through caspase activation and Bax cleavage mediated by calpain in SKOV-3 ovarian cancer cells. Cancer Lett 182: 83-92, 2002.

34. Budihardjo I, Oliver H,Lutter M,Luo X and Wang X: Biochemical pathways of caspase activation during apoptosis. Annu Rev Cell Dev Biol 15: 269-290, 1999.

35. van Gurp $M$, Festjens $N$, van Loo G, Saelens $X$ and Van den Abeele P: Mitochondrial intermembrane proteins in cell death. Biochem Biophys Res Commun 304: 487-497, 2003. 